\title{
Methods for improving the educational potential of students
}

\author{
Elena Pinevich ${ }^{1, *}$ and Olga Safaryan ${ }^{1}$ \\ ${ }^{1}$ Don State Technical University, 344003, Gagarin sq., 1, Rostov on Don, Russia
}

\begin{abstract}
This article is devoted to increasing students ' motivation to learn by means of internal settings set by the teacher to himself, aimed at establishing a common frequency with students. Along with numerous existing methods, the internal energy of the teacher plays a significant role. Research has shown that in the absence of this source for the teacher, the role of other methods is sufficiently reduced. If the flow of energy from the teacher finds its common channel with the flow radiated by students, and it will be on the same frequency, then the phenomenon of resonance occurs, the effect of the lesson will increase at times. Students under these conditions show results that exceed their own capabilities. A statistical study of the hypothesis put forward about the influence of waves of a certain frequency coming from the teacher on the thinking and motivational processes in learning is carried out. The statistical distribution of the sample is given. Numerical characteristics are calculated: sample average and sample variance. The law of distribution of performance indicators according to the point-rating system is established. The article proposes a twelve-level system of cognition with a core in the innovation.
\end{abstract}

\section{Introduction}

At present, there are quite a lot of recommendations on methods of conducting classes aimed at improving the effectiveness of the material being learned.

Let's review the main directions in pedagogy and the methods used in them.

Behaviorism.

It is based on behavior.

The founders are considered I. Pavlov, E. Thorndike, B. F. Skinner, J. Watson.

For behaviorists, it doesn't matter what the person thinks, but how they behave. External stimuli and expression are fundamental in learning. All psychophysical manifestations are chemical reactions of the body [1].

Educational technology uses:

1) Conditioned reflex.

2) The law of effect.

3) Operational behavior.

4) Reinforcement.

Cognitivism.

\footnotetext{
*Corresponding author: hpinevich@mail.ru
} 
It is based on knowledge [2].

The founders are L. S. Vygotsky, J. Atkinson, D. McClelland, N. Chomsky, and R. Shifrin.

For cognitive scientists, no matter how a person behaves, the main thing is mental abilities: attention, mentality, perception, words, thinking, memory, interpretation, categorization, generalization, problem solving [3-6].

There are six levels of learning in Bloom's taxonomy: a person must first know, understand, apply, analyze, synthesize, evaluate. Intel have added the 7 th level- to create.

Pedagogical technology.

Successful learning is based on a complex motivation of achievement, affiliation, and power.

Constructivism.

It is based on the construction of consciousness. Knowledge cannot be transmitted in its pure form. Each person constructs their own system of knowledge.

The founders are considered to be J. Dewey, H. Parkhurst, L.S. Vygotsky, J. Piaget, S. Papert.

Pedagogical technology.

The teacher creates the course structure, sets communication formats and protocols, aesthetic rules, and the degree of students ' activity. Students construct the material [7-11].

Instructivism.

Getting knowledge is based on certain instructions and algorithms.

The founders are considered to be St. Downs, J. Siemens.

Pedagogical technology.

Communication in a group in relation to the studied material is modeled. Information is received via the instructions [12-14].

For either method, the teacher should be an expert in understanding of students, knowledge of interests of students, building relationships with students, knowledge of material possession and technique of presentation, ability to conduct presentations and use video. The teacher should understand for himself what needs of students can be covered with readable material. And whether the student needs to know this in principle. It is necessary to convince the student what advantages they will get from this knowledge.

However, many teachers, knowing and applying these methods, do not get the desired result [15].

\section{Materials and methods}

The learning process is multi-step with complex components that depend on a large number of parameters.

The process of conducting the lesson, in fact, is the solution of a system with an infinite number of equations and an infinite number of unknowns.

What result can you get? If you decide correctly, it is very good, effective and fruitful. No computer program is currently capable of solving such a system. But the human brain can, if it wants to. The roots of such equations can coincide, be imaginary, complexconjugate and so on.

Just as in mathematics, not all the roots of an equation are real numbers, so in pedagogy there are imaginary solutions that some do not want, and many cannot realize. This is the energy that comes from both the teacher and the students.

The effect often depends not on the amount of material presented and knowledge of teaching methods, but on the internal state of the teacher, on internal attitudes and thoughts when presenting the material. It is something irrational, on the one hand, not to be contemplated, but it is contemplated. 
What should I do to teach them? First of all, you need to know the answers to the following questions for yourself.

Do I have training skills?

Do I want to teach?

Do I want to work in the educational institution?

Our brain will always find the answer to the question it formulates.

Information is perceived by a person as a stream of energy that is either directed at him or scattered around him. It all depends on whether the access channels are open or not. Whether the person is ready to accept it. Since energy flows are related to the speed of particles, it is important to create a certain charge for their perception.

A certain positive flow of energy must come from the teacher. If it is not available, then all known methods to strengthen motivation are ineffective. What are these flows related to? There are people who are charismatic and naturally able to attract others. But in General, the teacher must love what he is doing and be able to prove to everyone that his subject is really very interesting and important to a person.

And if the flow of energy from the teacher finds its common channel with the flow radiated by students, and has the same frequency with them, then there is a phenomenon called resonance, the effect of the lesson will increase at times. Students under these conditions show results that exceed their own capabilities.

What happens in this case?

Levels of cognitive activity are considered as a hierarchical connected system, the outer shell of which is the initial pedagogical energy. Let's draw concentric circles of the levels of knowledge leading from the beginning of knowledge acquisition to discovery (fig. 1).

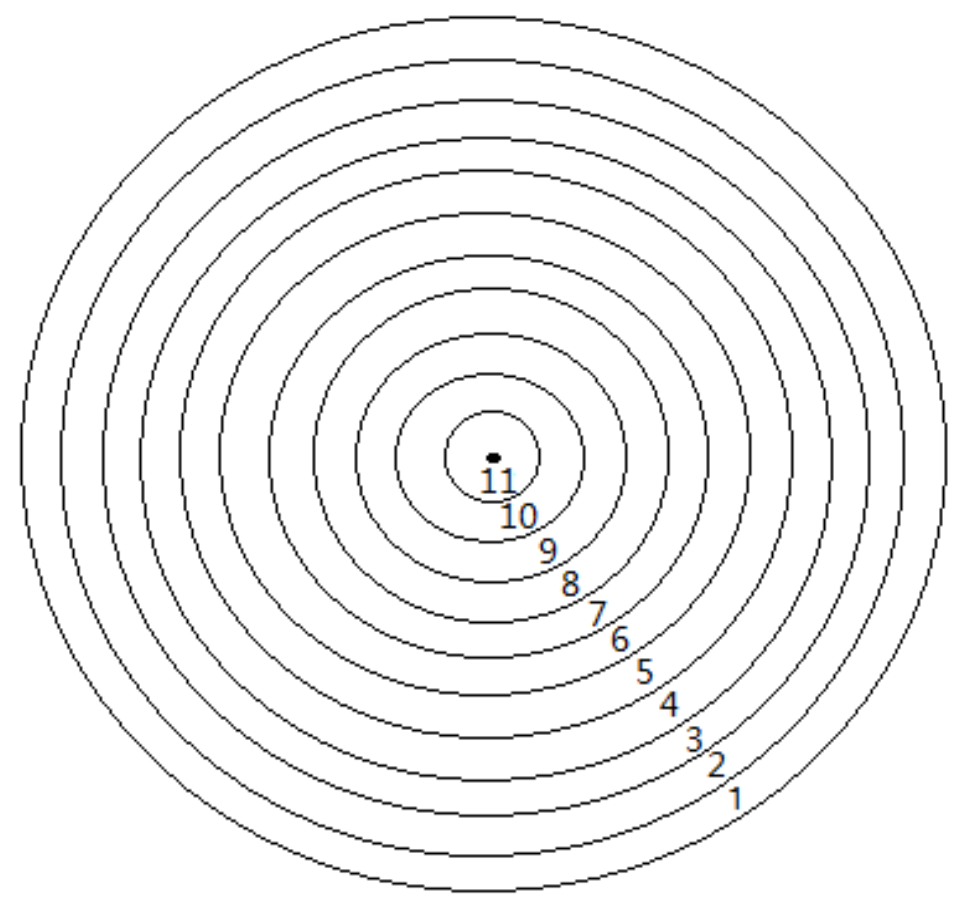

Fig. 1. The Concentric system of cognition

Consider each of these rings separately.

$1-$ Energy. 
In order to start the process of studying any material, it is necessary to have a certain amount of energy directed at the object of study. In the classroom, this energy must first be generated by the teacher, find a common frequency with a group of students, and then pass it on to the students.

2 - Need.

It is necessary to develop the need for this type of knowledge, based on the needs of the contingent.

3 - Interest.

Through the needs of students, the value of the studied material rises, which leads to the appearance of interest in it.

4 - Theoretical knowledge.

Theoretical knowledge can be divided into several types:

a) life knowledge (observations, events, phenomena, effects),

b) specific knowledge (data, axiomatic concepts, terminology, facts, theories),

c) abstract knowledge (numbers, letters, groups, structures, axioms, principles),

d) procedural knowledge (categories, directions, criteria, algorithms).

A student at this level can recognize information, name, list, demonstrate, denote, understand the meaning of the material, retell, describe, explain, and formulate the main features. He will know the answers to the questions: True or false? What? Where? When? Why? How? What is the main idea? What facts confirm it?

5 - Practical knowledge.

A student at this level can apply theoretical knowledge in solving various practical problems and examples; perform tasks on algorithms, translate. He will know the answers to the questions: What formulas, theorems, and algorithms can be used? What examples can I give? How do I solve?

6 - Application.

A student at this level may be able to transfer the theoretical knowledge obtained to a real practical situation, reformulate, implement and explain the theoretical solution in a practical language, use, predict, calculate, change, apply in a similar situation, translate a practical problem into the language of mathematics, computer programming; solve the problem using software packages. He will know the answers to the questions: What examples from life can be given? How do I formulate and build an issue?

7 - Creativity.

Students at this level can apply their theoretical knowledge by creating stories and creating tasks based on them, come up with designs, and participate in the search for applications and ideas. They will know the answers to the following questions: What problems can you come up with based on theoretical material on a given topic? What interesting things can be added to the theory being studied?

8 - Critical thinking.

A student at this level can substantiate or criticize ideas, put forward their point of view, challenge hypotheses, analyze, test, prove, and draw conclusions. He will know the answers to the questions: What happens if...? What are the possible results and consequences? How can this be proved?

9 - Differential thinking.

A student at this level can divide information, highlight the main thing, make tables, structure, and identify differences. He will know the answers to the questions: What is the main point? What are the criteria for grouping data? How do I separate one from the other?

10 - Integral thinking.

A student at this level can generalize, find connections, connect elements in a new way; group, systematize, combine, make a plan, algorithm. He will know the answers to such 
questions as: How do the facts relate to each other? What is common...? How do I link data groups, theories, and algorithms?

11 - Insight.

The researcher understands the essence of the new idea of the research object, puts forward a new hypothesis.

12 (core) - Discovery.

The researcher forms an idea, structures, creates, develops, conducts an experiment, confirms, proves, notifies.

\section{Research results}

During the use of pedagogical energy in the implementation of the educational process, observations were made on the performance of one hundred students of higher education institutions and recorded the results of increasing motivation to study on a one-hundredpoint scale. The results of the study are shown in table 1 .

Table 1. Increase in academic performance points

\begin{tabular}{|c|c|c|c|c|c|c|c|c|c|}
\hline № & Value & № & Value & № & Value & № & Value & № & Value \\
\hline 1 & 18 & 21 & 10 & 41 & 22 & 61 & 11 & 81 & 26 \\
\hline 2 & 35 & 22 & 32 & 42 & 23 & 62 & 20 & 82 & 4 \\
\hline 3 & 10 & 23 & 0 & 43 & 10 & 63 & 40 & 83 & 25 \\
\hline 4 & 22 & 24 & 21 & 44 & 24 & 64 & 20 & 84 & 18 \\
\hline 5 & 30 & 25 & 50 & 45 & 25 & 65 & 15 & 85 & 26 \\
\hline 6 & 21 & 26 & 20 & 46 & 13 & 66 & 21 & 86 & 15 \\
\hline 7 & 17 & 27 & 20 & 47 & 26 & 67 & 23 & 87 & 24 \\
\hline 8 & 20 & 28 & 12 & 48 & 26 & 68 & 23 & 88 & 20 \\
\hline 9 & 20 & 29 & 25 & 49 & 29 & 69 & 0 & 89 & 45 \\
\hline 10 & 25 & 30 & 35 & 50 & 26 & 70 & 22 & 90 & 20 \\
\hline 11 & 25 & 31 & 26 & 51 & 19 & 71 & 21 & 91 & 25 \\
\hline 12 & 28 & 32 & 45 & 52 & 22 & 72 & 20 & 92 & 24 \\
\hline 13 & 10 & 33 & 19 & 53 & 23 & 73 & 19 & 93 & 14 \\
\hline 14 & 25 & 34 & 25 & 54 & 14 & 74 & 21 & 94 & 25 \\
\hline 15 & 20 & 35 & 26 & 55 & 20 & 75 & 26 & 95 & 13 \\
\hline 16 & 25 & 36 & 12 & 56 & 40 & 76 & 14 & 96 & 18 \\
\hline 17 & 17 & 37 & 25 & 57 & 18 & 77 & 20 & 97 & 16 \\
\hline 18 & 27 & 38 & 30 & 58 & 25 & 78 & 18 & 98 & 17 \\
\hline 19 & 16 & 39 & 13 & 59 & 36 & 79 & 21 & 99 & 20 \\
\hline 20 & 25 & 40 & 19 & 60 & 19 & 80 & 11 & 100 & 20 \\
\hline
\end{tabular}

One-hundred-point scale was divided into 10 intervals and frequencies were calculated for each of them. If the number $x_{i}$ coincided with the beginning of the interval, it was entered in this interval; if the number $x_{i}$ coincided with the end of the interval, it was entered in the next interval. The results are shown in the table 2.

Table 2. Table of frequencies

\begin{tabular}{|c|c|c|c|}
\hline № & Intervals & $\boldsymbol{x}_{\boldsymbol{i}}$ & $\boldsymbol{n}_{\boldsymbol{i}}$ \\
\hline 1 & $0-10$ & 5 & 3 \\
\hline 2 & $10-20$ & 15 & 31 \\
\hline 3 & $20-30$ & 25 & 55 \\
\hline 4 & $30-40$ & 35 & 6 \\
\hline 5 & $40-50$ & 45 & 4 \\
\hline 6 & $50-60$ & 55 & 1 \\
\hline 7 & $60-70$ & 65 & 0 \\
\hline
\end{tabular}




\begin{tabular}{|c|c|c|c|}
\hline 8 & $70-80$ & 75 & 0 \\
\hline 9 & $80-90$ & 85 & 0 \\
\hline 10 & $90-100$ & 95 & 0 \\
\hline
\end{tabular}

$x_{i}-$ is the midpoint of the intervals,

$n_{i}-$ frequencies.

The sample average was found by the formula:

$$
\begin{gathered}
\overline{x_{b}}=\frac{\sum_{i=1}^{k} x_{i} n_{i}}{\sum_{i=1}^{k} n_{i}} \\
\overline{x_{b}}=\frac{5 \cdot 3+15 \cdot 31+25 \cdot 55+35 \cdot 6+45 \cdot 4+55 \cdot 1}{100}=23 .
\end{gathered}
$$

The sample variance was calculated using the formula:

$$
\overline{D_{b}}=\frac{\sum_{i=1}^{k}\left(x_{i}-\overline{x_{b}}\right)^{2} n_{i}}{\sum_{i=1}^{k} n_{i}}
$$

$\overline{D_{b}}=\frac{(5-23)^{2} \cdot 3+(15-23)^{2} \cdot 31+(25-23)^{2} \cdot 55+(35-23)^{2} \cdot 6+(45-23)^{2} \cdot 4+(55-23)^{2} \cdot 1}{100}=70$.

The mean square deviation was found by the formula:

$$
\overline{S_{b}}=\sqrt{\overline{D_{b}}}
$$

$\overline{S_{b}} \approx 8,37$.

We obtained a histogram of the frequency distribution (fig. 2).

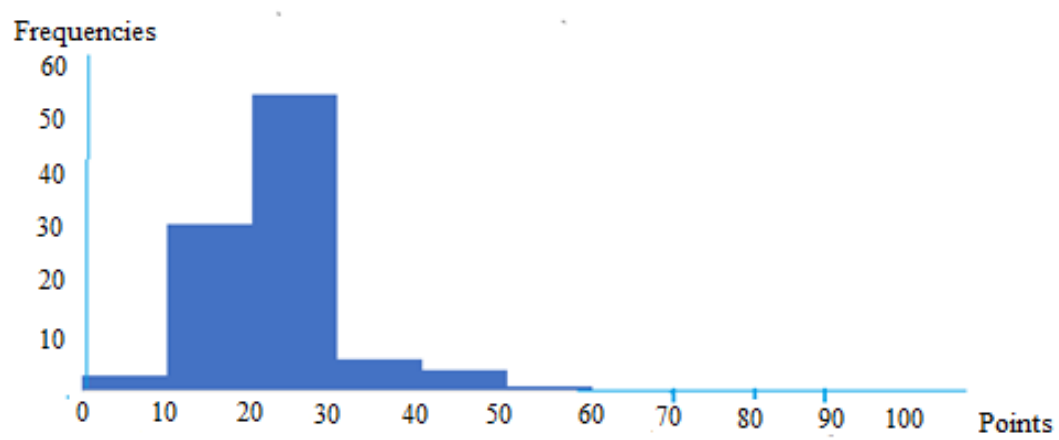

Fig. 2. Frequency histogram

Based on the type of the histogram and the assumed type of the empirical curve, we put forward the hypothesis $H_{0}$ about the normal distribution.

Let's check the hypothesis about the normal distribution law of the General selection by the Pearson criterion. Using table 3, we will find $\chi_{v}^{2}$. 
Table 3. Data for finding $\chi_{v}^{2}$

\begin{tabular}{|c|c|c|c|c|c|}
\hline $\boldsymbol{x}_{\boldsymbol{i}}$ & $\boldsymbol{n}_{\boldsymbol{i}}$ & $\boldsymbol{t}_{\boldsymbol{i}}$ & $\varphi\left(t_{i}\right)$ & $n_{i}^{\prime}$ & $\frac{\left(n_{i}-n_{i}^{\prime}\right)^{2}}{n_{i}^{\prime}}$ \\
\hline 5 & & & & & 0,8 \\
\hline 15 & 3 & $-2,150538$ & 0,0404 & 5 & 5,4468 \\
\hline 25 & 55 & $-0,955795$ & 0,3972 & 47 & 1,3617 \\
\hline 35 & 6 & 0,238949 & 0,3894 & 47 & 8 \\
\hline 45 & 4 & 2,62843692 & 0,1456 & 18 & - \\
\hline 55 & 1 & 3,823178 & 0,0129 & 2 & - \\
\hline 65 & 0 & 5,017921 & - & - & - \\
\hline 75 & 0 & 6,212664 & - & - & - \\
\hline 85 & 0 & 7,407407 & - & - & - \\
\hline 95 & 0 & 8,602151 & - & - & \\
\hline
\end{tabular}

$$
\chi_{v}^{2}=\sum_{i=1}^{k} \frac{\left(n_{i}-n_{i}^{\prime}\right)^{2}}{n_{i}^{\prime}}
$$

Then $\mathrm{z}=7, \chi_{v}^{2}=17,6085$. For $\mathrm{z}=7, \alpha=0,005$, we get $\chi_{c r}^{2}=20,3$.

$$
\chi_{v}^{2}<\chi_{c r}^{2}
$$

therefore, we accept the $H_{0}$ hypothesis of a normal distribution.

\section{Conclusions}

Since each student uniquely rebuilds his line of learning and interaction in the lesson, the most important role in conducting the lesson is not only the words, but the thoughts of the teacher. Depending on the internal settings that the teacher programs his brain, his actions will be arranged. The energy directed to the success of students will be reflected in the creative potential and is the starting point of learning.

\section{Discussion}

One of the goals of training is considered to teach students to think. To think like? Everyone is already thinking (about something of their own). We must teach you to think creatively and constructively.

In the process of learning, students themselves must expand the boundaries of what they have heard, find material and justify the need for this information, in fact, create a course, a 
textbook, a space, and discoveries for themselves. Students should construct their own knowledge, not passively receive information.

Is there a key to executing this algorithm?

This is a very complex thing, depending on many parameters. In order to understand, you need to look deep into yourself.

You should go to class with thoughts that generate a certain type of energy: "How do I build a job so that learning is fun, so that students want to stay in class and come back again, so that they work there with passion and learn the material with passion." Any student can be made unhappy in the classroom, just as well as happy, and the learning process can be turned into a very exciting activity.

If a student is given a task and told to do it without bringing it to the level of possibilities, then he, after trying several times, will give up this activity, releasing all the energy in vain. It will seem to him that he has chosen the wrong direction, he is not coping well, he is not interested in it. However, this activity can also be turned into an exciting process in which the potential of students will be revealed, there will be freedom of research. To do this, each meeting with students in the classroom should be made so valuable that the student appreciates the very fact of meeting with the teacher. In order for that to happen a teacher in addition to applying known techniques needs to organize their thoughts in the following direction: to go to class with thoughts of how to help the student interested in the discipline, how to bind possible research areas to the needs of the student. It is necessary to show that you are not indifferent whether the student succeeds or fails.

They say: "Hard work leads to success." Everyone knows this statement. However, the same phrase also pushes many people away from work, the body begins to protect itself from an unbearable load. And vice versa, if you say to yourself: "I'm going to do a little...", then it's not a big deal for the brain. After all, we are not talking about overload. And after this phrase, you can sit and study for hours without being afraid that it is hard.

And then we finally come to the fact that we work 24 hours a day, 7 days a week, while being happy and having a lucky streak in life.

Effective learning, like any other work, should be built in such a way that it is a joy, not a burden.

Since learning is a social process, an important role is human interaction: between teacher and students and between students themselves, between the teacher and the management, between management and students. And positive thoughts in subjects with this interaction will help to model rapport. There is a subconscious understanding of the essence of another subject with whom you enter into communication. Students on a subconscious level begin to understand the teacher's attitudes and through the prism of his topic. There is a need for discovery, improvement and development of something new. There is a need to know the material presented in the lesson.

By generating the same frequency with students and identifying their needs and further increasing the value of the material presented, the teacher raises motivation. The student begins to perceive the material as meaningful, valuable, and important. Young people try to unlock themselves abilities in it.

Based on the experience of previous years, I want to note that this effect occurs regardless of the level of intelligence of the group, the attitude to learning and the responsibility of students. If the group is weak and irresponsible, without interest in learning, then if the teacher first melts the ice with his thoughts, and lights a spark of interest, then students, starting from scratch, reach a fanatical passion for the discipline. As a dormant volcano spills magma from its vent, so students begin to make up for lost years, trying to bring something new and interesting to science.

\section{References}


1. A. P. Blaisdell, Cognitive Dimension of Operant Learning. Learning and Memory: A Comprehensive Reference (Second Edition), 85-110 (2017)

2. N. Tsuchiya, T. Andrillon, A. Haun, A reply to "the unfolding argument": Beyond functionalism behaviorism and towards a science of causal structure theories of consciousness. Consciousness and Cognition, 79, 102877 (2020) doi:10.1016/j.concog.2020.102877

3. M. Manolescu, School Competence between Behaviourism and Cognitivism or the Cognitive Approach to Schooling. Procedia - Social and Behavioral Sciences, 76, 912 916 (2013)

4. K. J. Wölfling, K. W. Müller, M. E. Beutel, AS32-02 - Treating internet addiction: first results on efficacy of a standardized cognitiv-behavioral therapeutic approach. European Psychiatry, 27, 1 (2012)

5. K. Mehmet, A. Hakan, A Theoretical Analysis of Moocs Types from a Perspective of Learning Theories. Procedia - Social and Behavioral Sciences, 186, 15-19 (2015)

6. W. Wen-Hsiung, C. Wen-Bin, K. Hao-Yun, A. H. Chung-Hsing, H. Sih-Han, Reexploring game-assisted learning research: The perspective of learning theoretical bases. Computers \& Education, 59(4), 1153-1161 (2012)

7. M. F. Aqda, F. Hamidi, F. Ghorbandordinejad, The impact of constructivist and cognitive distance instructional design on the learner's creativity. Procedia Computer Science, 3, 260-26 (2011) doi:10.1016/j.procs.2010.12.044

8. H. M. Iqbal, Cognitive Development, Educational Theories of International Encyclopedia of the Social \& Behavioral Sciences (Second Edition), 51-57 (2015)

9. K. Sevinc, Use of constructivist approach in architectural education / Procedia - Social and Behavioral Sciences, 15, 3980-3988 (2011) doi: 10.1016/j.sbspro.2011.04.402

10. I. Blau, T. Shamir-Inbal, O. Avdjel, How does the pedagogical design of a technologyenhanced collaborative academic course promote digital literacies, self-regulation, and perceived learning of students? The Internet and Higher Education, 45, 165-194 (2020) doi: 10.1016/j.sbspro.2011.04.402

11. B. T. Duane, M. E. Satre, Utilizing constructivism learning theory in collaborative testing as a creative strategy to promote essential nursing skills. Nurse Education TodayJanuary, 34(1), 31-34 (2014)

12. A. Loureiro, T. Bettencourt, The Use of Virtual Environments as an Extended Classroom - A Case Study with Adult Learners in Tertiary Education. Procedia Technology, 13, 97-106 (2014) doi: 10.1016/j.protcy.2014.02.013

13. J. R. Gallagher, The Ethics of Writing for Algorithmic Audiences. Future Generation Computer Systems. August 2020

14. M. Klement, M. Chráska, S. Klementová, Explanation of Instruments and Procedures Used by the Recipients of Education in order to Build their Own Learning Network, Based on the Generic Model Cognitive Process. Procedia - Social and Behavioral Sciences, 12, 174, 1614-1622 (2015)

15. C.-Chung, G. Y. Chengb, S. Shibatac, A triarchal instruction model: integration of principles from Behaviorism, Cognitivism, and Humanism. Procedia - Social and Behavioral Sciences, 9, 105-118 (2010) doi:10.1016/j.sbspro.2010.12.122 